\title{
Collectable Amounts of Straw Resources and Their Distribution in China
}

\author{
Binling $\mathrm{Ai}^{1, \mathrm{a}}$, Zhanwu Sheng ${ }^{1, \mathrm{~b}}$, Lili Zheng ${ }^{1, \mathrm{c}}$ and Wenting Shang ${ }^{2, \mathrm{~d}}$ \\ ${ }^{1}$ Haikou Experimental Station, Chinese Academy of Tropical Agricultural Sciences, Haikou, Hainan \\ 570102, China \\ ${ }^{2}$ College of Food Science and Technology, Hainan University, Haikou, Hainan 570228, China \\ aaibinling@163.com, bshengzhanwu100@163.com, 'lily_0909@126.com, dhuikudeyuswt@163.com
}

Keywords: straw resources; Straw-grain ratio; collectable coefficient; collectable amount; distribution

Abstract. Crop straw is a valuable renewable resource, which holds great potential to be developed further. The estimation of the yield and collectable amount of crop straw is a foundation for its comprehensive utilization. Based on the output of major farm products, the collectable amounts of different kinds of crop straw in China and their distribution were estimated in this study. China holds enormous crop straw resources, and more than $60986.1 \times 10^{4}$ t of straw resources could be collected in 2014. Corn stalk, rice straw and wheat straw were the three most abundant crop straws, whose collectable amounts in 2013 reached $21481.0 \times 10^{4}, 15420.1 \times 10^{4}$ and $11519.4 \times 10^{4} \mathrm{t}$, accounting for $35.2 \%, 25.3 \%$ and $18.9 \%$ of the total collectable crop straw, respectively. Henan, Heilongjiang and Shandong were the richest provinces in straw resources, where the collectable amounts of the three crop straws reached $6142.1 \times 10^{4}, 5901.0 \times 10^{4}$ and $4894.5 \times 10^{4}$ t, accounting for $10.6 \%, 10.2 \%$ and $8.4 \%$ of total collectable amount of those in China, respectively.

\section{Introduction}

The product of crop photosynthesis includes both the seeds and the straw from harvested crops. As inevitable by-product in agricultural production, crop straw is produced in huge quantity every year. Crop straw is a valuable renewable resource, and its comprehensive utilization plays an important role in the sustainable development of agriculture. The estimation of the yield and collectable amounts of straw resources is one of the foundations of the utilization of crop straw. Many studies on estimation of straw resources have been performed using different methods, however, with large-scale differences in those calculation results [1-3]. In this study, based on the outputs of major farm products from authoritative data sources, the reserves and collectable amounts of different kinds of straw resources in China were estimated. In addition, the distribution of the three major crop straws, corn stalk, rice straw and wheat straw, was analyzed.

\section{Methods}

All the outputs data of major farm products comes from China Statistical Yearbook 2014 and the web site of National Bureau of Statistics of China [4].

Straw-grain ratio $\left(S_{G}\right)$ refers to the ratio of yield of crop straw to output of main product of the crops. The straw-grain ratios used in this paper are referenced from a previous study [5]. The reserve of crop straw $\left(W_{S}\right)$ is calculated from Eq.1.

$$
W_{S}=W_{P} \times S_{G},
$$

where $W_{P}$ is the output of main product of the crop and $S_{G}$ the straw-grain ratio.

The collectable amounts

The collectable amount of straw resource refers to the maximum quantity of crop straw that can be collected from the field for further utilization in the actual operations of farming and harvesting management. The collectable amount of crop straw $\left(W_{G S}\right)$ is calculated from Eq.2.

$$
W_{G S}=W_{S} \times I_{G} \text {, }
$$

where $W_{S}$ is the yield of crop straw and $I_{G}$ the collectable coefficient referring to the proportion of collectable and utilizable crop straw in total yield of crop straw. The collectable coefficients used in this paper are referenced from a previous study [6]. 


\section{Results}

\subsection{Estimation results of crop straw resources in China}

As a major country of grain production, China has enormous crop straw resources. Based on the output data of major farm products from China Statistical Yearbook 2014 and the relevant data from the National Bureau of Statistics of China, and referencing the straw-grain ratios described in a previous study [5], the yields of crop straw in China in the last three years were calculated (Table 1). Taking straw resources produced in 2014 as an example, the output of main crop straw in China reached $72836.9 \times 10^{4} \mathrm{t}$, and the yields of corn stalk, rice straw and wheat straw were $25880.8 \times 10^{4}$, $18578.4 \times 10^{4}$ and $13878.8 \times 10^{4} \mathrm{t}$, accounting for $35.4 \%, 25.5 \%$ and $18.7 \%$ of the total quantity of crop straw, respectively. As the three major straw resources, the reserve of corn stalk, rice straw and wheat straw contributed nearly $80 \%$ to the total output of the agricultural crop straw, which holds great potential to be developed further.

Table 1 National estimated amounts of crop straw resources in 2012-2014

\begin{tabular}{lllllllll}
\hline Crops & $\begin{array}{l}\text { Grain- } \\
\text { straw }\end{array}$ & \multicolumn{2}{l}{ Output of farm products $\left(\times 10^{4} \mathrm{t}\right)$} & \multicolumn{2}{l}{ Straw yield $\left(\times 10^{4} \mathrm{t}\right)$} & \multicolumn{2}{l}{$\begin{array}{l}\text { Percent in } \\
\text { total } \\
\text { straw }(\%)\end{array}$} \\
& ratios & 2012 & 2013 & 2014 & 2012 & 2013 & 2014 & 25.5 \\
Rice & 0.9 & 20423.6 & 20361.2 & 20642.7 & 18381.2 & 18325.1 & 18578.4 & 25.8 \\
Wheat & 1.1 & 12102.3 & 12192.6 & 12617.1 & 13312.5 & 13411.9 & 13878.8 & 18.7 \\
Corn & 1.2 & 20561.4 & 21848.9 & 21567.3 & 24673.7 & 26218.7 & 25880.8 & 35.4 \\
Beans & 1.6 & 1730.5 & 1595.3 & 1625.7 & 2768.8 & 2552.5 & 2601.1 & 3.7 \\
Tubers & 0.5 & 3292.8 & 3329.3 & 3357.3 & 1646.4 & 1664.7 & 1678.7 & 2.3 \\
Peanuts & 0.8 & 1669.2 & 1697.2 & 1648.2 & 1335.4 & 1357.8 & 1318.6 & 1.9 \\
Rapeseeds & 1.5 & 1400.7 & 1445.8 & 1477.2 & 2101.1 & 2168.7 & 2215.8 & 3.0 \\
Sesame & 2.2 & 63.9 & 62.3 & 63.0 & 140.6 & 137.2 & 138.6 & 0.2 \\
Cotton & 3.4 & 683.6 & 629.9 & 616.1 & 2324.2 & 2141.7 & 2094.7 & 3.0 \\
Fiber crops & 1.9 & 26.1 & 22.9 & 23.1 & 49.6 & 43.6 & 43.9 & 0.1 \\
Sugarcane & 0.3 & 12311.4 & 12820.1 & 12561.1 & 3693.4 & 3846.0 & 3768.3 & 5.2 \\
Beetroots & 0.2 & 1174.0 & 926.0 & 800.0 & 234.8 & 185.2 & 160.0 & 0.3 \\
Tobacco & 1.6 & 340.7 & 337.4 & 299.5 & 545.1 & 539.8 & 479.2 & 0.7 \\
Total & - & 75780.2 & 77269.0 & 77298.3 & 71206.8 & 72592.7 & 72836.9 & 100 \\
\hline
\end{tabular}

\subsection{Estimation results of collectable amounts of straw resources in China}

Based on the estimated amount of straw resources (Table 1), and according to the collectable coefficients confirmed by the previous study [6], the collectable amounts of various types of crop straw were calculated and presented in Table 2. The estimation results showed that the total amount of straw resources can be collected in China in 2014 was about $60986.1 \times 10^{4} \mathrm{t}$, and about $16 \%$ of crop straw was remained in the field or wasted in the collection process. Corn stalk, rice straw and wheat straw were the three most abundant crop straw resources which contributed nearly $80 \%$ to the total collectable reserves. The collectable corn stalk, rice straw and wheat straw were $21481.0 \times 10^{4}$, $15420.1 \times 10^{4}$ and $11519.4 \times 10^{4}$ t, accounting for $35.2 \%, 25.3 \%$ and $18.9 \%$ of the total collectable crop straw, respectively.

Table 2 Total yield and collectable amounts of straw resource in 2014

\begin{tabular}{lllll}
\hline Straw types & Straw yield $\left(\times 10^{4} \mathrm{t}\right)$ & $\begin{array}{l}\text { Collectable } \\
\text { coefficient }\end{array}$ & $\begin{array}{l}\text { Collectable } \\
\text { amount }\left(\times 10^{4} \mathrm{t}\right)\end{array}$ & $\begin{array}{l}\text { Percent in total } \\
\text { collectable amount (\%) }\end{array}$ \\
\hline Rice straw & 18578.4 & 0.83 & 15420.1 & 25.3 \\
Wheat straw & 13878.8 & 0.83 & 11519.4 & 18.9 \\
Corn stalk & 25880.8 & 0.83 & 21481.0 & 35.2 \\
Beans straw & 2601.1 & 0.88 & 2289.0 & 3.8 \\
Tubers vine & 1678.7 & 0.80 & 1342.9 & 2.2 \\
\hline
\end{tabular}


Continued from Table 2

\begin{tabular}{lllll}
\hline Straw types & Straw yield $\left(\times 10^{4} \mathrm{t}\right)$ & $\begin{array}{l}\text { Collectable } \\
\text { coefficient }\end{array}$ & $\begin{array}{l}\text { Collectable } \\
\text { amount }\left(\times 10^{4} \mathrm{t}\right)\end{array}$ & $\begin{array}{l}\text { Percent } \\
\text { collectable amount }(\%)\end{array}$ \\
\hline Peanuts vine & 1318.6 & 0.85 & 1120.8 & 1.8 \\
Rapeseeds stalk & 2215.8 & 0.85 & 1883.4 & 3.1 \\
Sesame stalk & 138.6 & 0.85 & 117.8 & 0.2 \\
Cotton stalk & 2094.7 & 0.90 & 1885.3 & 3.1 \\
Fiber crops stalk & 43.9 & 0.87 & 38.2 & 0.1 \\
Sugarcane bagasse & 3768.3 & 0.88 & 3316.1 & 5.4 \\
Beetroots pulp & 160.0 & 0.88 & 140.8 & 0.2 \\
Tobacco stalk & 479.2 & 0.90 & 431.3 & 0.7 \\
Total & & 60986.1 & 100.0 \\
\hline
\end{tabular}

\subsection{Distribution of main straw resources in China}

In recent years, the yield of crop straw in China is increasing. Due to the different geographical position and climatic condition, the distribution and collectable amounts of different crop straws are also different. Table 3 presents the provincial data of collectable amounts of corn stalk, rice straw and wheat straw in recent three years. In 2013, for example, corn stalk is the most abundant straw resources, whose output accounted for $35 \%$ of main crop straw production. The collectable corn stalk mainly distributed in north-eastern provinces, such as Heilongjiang, Jilin and Liaoning, and north China, such as Henan, Hebei, Shandong, Inner Mongolia and Shanxi. Rice straw is the second most abundant straw resources, accounting for $25 \%$ of main crop straw production, which is mainly distributed in south China and east China, such as Hunan, Hubei, Sichuan, Jiangxi, Jiangsu, Anhui, Guangxi and Guangdong, and Heilongjiang province in northeastern China. As the third largest straw resources, wheat straw accounted for about 19\% of the main crop straw production, mainly distributing in Henan, Hebei, Shandong, Anhui and Jiangsu provinces. Henan province, Heilongjiang province and Shandong province had the largest quantities of straw resources, in which the yields of those three crop straws were $6142.1 \times 10^{4}, 5901.0 \times 10^{4}$ and $4894.5 \times 10^{4} \mathrm{t}$, accounting for $10.6 \%, 10.2 \%$ and $8.4 \%$ of total collectable amount of those three crop straws in China, respectively.

Table 3 Provincial estimated amounts of corn stalk, rice straw and wheat straw in 2011-2013

\begin{tabular}{llllllllll}
\hline Provinces & \multicolumn{2}{l}{ Corn stalk $\left(\times 10^{4} \mathrm{t}\right)$} & \multicolumn{3}{c}{ Rice straw $\left(\times 10^{4} \mathrm{t}\right)$} & \multicolumn{4}{c}{ Wheat straw $\left(\times 10^{4} \mathrm{t}\right)$} \\
& 2011 & 2012 & 2013 & 2011 & 2012 & 2013 & 2011 & 2012 & 2013 \\
\hline Beijing & 90.0 & 83.2 & 74.9 & 0.1 & 0.1 & 0.1 & 25.9 & 25.1 & 17.1 \\
Tianjin & 94.0 & 92.0 & 101.8 & 8.0 & 8.4 & 9.6 & 49.5 & 50.9 & 52.3 \\
Hebei & 1633.1 & 1642.9 & 1697.1 & 45.0 & 37.2 & 43.9 & 1165.1 & 1221.3 & 1266.5 \\
Shanxi & 851.2 & 900.2 & 951.7 & 0.4 & 0.4 & 0.5 & 219.4 & 236.6 & 210.7 \\
Inner & 1625.6 & 1777.3 & 2061.5 & 58.2 & 54.7 & 41.8 & 156.0 & 172.1 & 164.7 \\
Mongolia & & & & & & & & & \\
Liaoning & 1354.9 & 1417.8 & 1556.9 & 377.3 & 379.3 & 378.6 & 3.4 & 2.9 & 2.5 \\
Jilin & 2329.6 & 2568.4 & 2764.6 & 465.8 & 390.7 & 420.7 & 1.2 & 1.2 & 0.0 \\
Heilongjiang & 2665.0 & 2876.4 & 3203.6 & 1540.4 & 1621.9 & 1658.8 & 94.8 & 63.9 & 35.5 \\
Shanghai & 2.7 & 2.5 & 2.5 & 66.4 & 66.6 & 64.8 & 22.0 & 20.6 & 16.1 \\
Jiangsu & 225.3 & 229.2 & 215.6 & 1392.5 & 1419.4 & 1435.9 & 934.2 & 957.5 & 1005.5 \\
Zhejiang & 14.5 & 29.1 & 26.6 & 484.8 & 454.3 & 433.4 & 24.7 & 24.7 & 25.4 \\
Anhui & 361.1 & 425.8 & 424.3 & 1036.2 & 1041.0 & 1017.7 & 1110.0 & 1181.4 & 1216.1 \\
Fujian & 16.5 & 17.9 & 19.2 & 384.0 & 376.3 & 375.0 & 0.7 & 0.7 & 0.6 \\
Jiangxi & 10.5 & 12.5 & 12.0 & 1456.7 & 1476.1 & 1497.0 & 2.0 & 2.1 & 2.2 \\
Shandong & 1970.8 & 1986.5 & 1959.3 & 77.7 & 77.2 & 77.4 & 1920.9 & 1989.9 & 2025.8 \\
Henan & 1689.7 & 1740.8 & 1789.3 & 354.5 & 367.9 & 362.9 & 2851.3 & 2900.9 & 2945.8 \\
Hubei & 275.1 & 281.5 & 269.7 & 1207.8 & 1233.5 & 1252.5 & 314.8 & 281.0 & 380.6 \\
Hunan & 187.7 & 196.5 & 184.3 & 1923.9 & 1965.9 & 1913.5 & 9.3 & 7.8 & 10.0 \\
\hline
\end{tabular}


Continued from Table 3

\begin{tabular}{llllllllll}
\hline Provinces & \multicolumn{3}{l}{ Corn stalk $\left(\times 10^{4} \mathrm{t}\right)$} & \multicolumn{3}{c}{ Rice straw $\left(\times 10^{4} \mathrm{t}\right)$} & \multicolumn{3}{c}{ Wheat straw $\left(\times 10^{4} \mathrm{t}\right)$} \\
& 2011 & 2012 & 2013 & 2011 & 2012 & 2013 & 2011 & 2012 & 2013 \\
\hline Guangdong & 78.6 & 79.3 & 81.3 & 819.4 & 841.5 & 780.6 & 0.2 & 0.2 & 0.3 \\
Guangxi & 243.8 & 249.6 & 264.9 & 809.8 & 853.1 & 863.7 & 0.2 & 0.2 & 0.2 \\
Hainan & 10.3 & 11.3 & 12.0 & 108.4 & 116.4 & 112.0 & 0.0 & 0.0 & 0.0 \\
Chongqing & 256.0 & 255.2 & 257.1 & 368.7 & 372.0 & 375.8 & 38.7 & 35.1 & 30.8 \\
Sichuan & 698.8 & 698.5 & 759.4 & 1140.8 & 1147.5 & 1157.5 & 398.1 & 399.0 & 384.6 \\
Guizhou & 242.8 & 340.9 & 296.8 & 227.0 & 300.6 & 269.9 & 46.0 & 47.8 & 47.1 \\
Yunnan & 595.9 & 697.2 & 731.2 & 499.5 & 481.5 & 498.9 & 90.3 & 80.6 & 73.5 \\
Tibet & 2.7 & 2.6 & 2.5 & 0.4 & 0.4 & 0.4 & 22.7 & 22.4 & 22.0 \\
Shaanxi & 548.5 & 564.6 & 584.4 & 63.2 & 65.2 & 68.0 & 375.2 & 397.7 & 355.9 \\
Gansu & 423.9 & 502.1 & 569.2 & 0.0 & 2.9 & 2.8 & 226.0 & 254.5 & 215.4 \\
Qinghai & 15.1 & 16.9 & 16.4 & 0.0 & 0.0 & 0.0 & 32.3 & 32.1 & 32.9 \\
Ningxia & 171.7 & 190.4 & 205.4 & 52.9 & 53.3 & 51.5 & 57.5 & 56.6 & 42.2 \\
Xinjiang & 515.6 & 589.7 & 666.3 & 45.3 & 42.1 & 44.7 & 526.5 & 526.4 & 549.7 \\
China & 19201.0 & 20479.2 & 21761.5 & 15014.8 & 15247.4 & 15232.2 & 10718.7 & 10993.1 & 11131.9 \\
\hline
\end{tabular}

\section{Conclusions}

China holds enormous crop straw resources. Estimated from the outputs data of major farm products from National Bureau of Statistics of China, more than $60986.1 \times 10^{4} \mathrm{t}$ of straw resources can be collected in China in 2014. The collectable corn stalk, rice straw and wheat straw were $21481.0 \times 10^{4}$, $15420.1 \times 10^{4}$ and $11519.4 \times 10^{4}$ t, accounting for $35.2 \%, 25.3 \%$ and $18.9 \%$ of total amount of collectable straw, respectively. Henan, Heilongjiang and Shandong were the richest provinces in straw resources, where the collectable quantities of the three crop straws reached $6142.1 \times 10^{4}$, $5901.0 \times 10^{4}$ and $4894.5 \times 10^{4} \mathrm{t}$, respectively.

\section{Acknowledgements}

This work was financially supported by the Natural Science Foundation of Hainan Province (Grant No. 20154194) and the Fundamental Scientific Research Funds for Chinese Academy of Tropical Agricultural Sciences (Project No. 1630052015044).

\section{References}

[1] Y. Yang, P. Zhang, W. Zhang, Y. Tian, Y. Zheng, L. Wang: Renew. Sust. Energ. Rev. Vol. 14 (2010), p. 3050-3058.

[2] Y. Cai, H. Qiu, Z. Xu: J. Nat. Resour. Vol. 26 (2011), p. 1637-1646. (In Chinese)

[3] H. Long, X. Li, H. Wang, J. Jia: Renew. Sust. Energ. Rev. Vol. 26, (2013), p. 344-352.

[4] Information on http://data.stats.gov.cn/

[5] Y. Bi, C. Gao, Y. Wang, B. Li: Transactions of the CSAE Vol. 25 (2009), p. 211-217. (In Chinese)

[6] Y. Wang, Y. Bi, C. Gao: Scientia Agricultura Sinica Vol. 43 (2010), p. 1852-1859. (In Chinese) 